
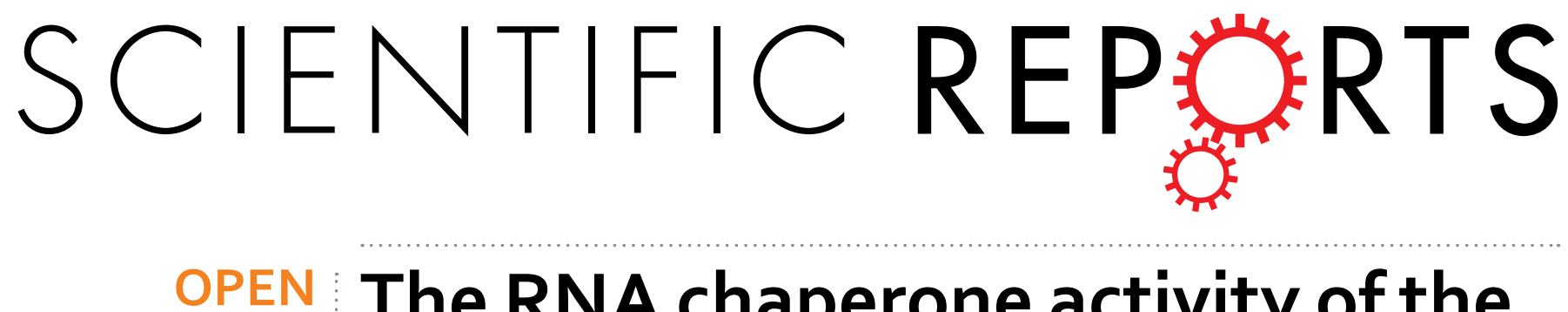

Received: 13 October 2015

Accepted: 09 December 2015

Published: 19 January 2016

\title{
The RNA chaperone activity of the Trypanosoma brucei editosome raises the dynamic of bound
} pre-mRNAs

\author{
W.-Matthias Leeder, Christin Voigt, Michael Brecht \& H. Ulrich Göringer
}

Mitochondrial transcript maturation in African trypanosomes requires an RNA editing reaction that is characterized by the insertion and deletion of $U$-nucleotides into otherwise non-functional mRNAs. The reaction is catalyzed by editosomes and requires guide $(\mathrm{g}) \mathrm{RNAs}$ as templates. Recent data demonstrate that the binding of pre-edited mRNAs to editosomes is followed by a chaperone-type RNA remodeling reaction. Here we map the changes in RNA folding using selective 2 ' -hydroxyl acylation analyzed by primer extension (SHAPE). We demonstrate that pre-mRNAs in their free state adopt intricately folded, highly stable 2D-structures. Editosome binding renders the pre-mRNAs to adopt 2D-conformations of reduced stabilities. On average about $30 \%$ of the nucleotides in every pre-mRNA are affected with a prevalence for $U$-nucleotides. The data demonstrate that the chaperone activity acts by increasing the flexibility of U-residues to lower their base-pairing probability. This results in a simplified RNA folding landscape with a reduced energy barrier to facilitate the binding of gRNAs. The data provide a first rational for the enigmatic $\mathrm{U}$-specificity of the editing reaction.

RNA chaperones catalyze the formation of the thermodynamically most stable RNA conformation by lowering the energetic barriers between misfolded RNA populations and by mediating the unwinding and refolding of non-functional RNA conformations ${ }^{1-4}$. As a consequence of that function, cells express a whole gamut of RNA chaperones, ATP-dependent RNA helicases and RNA annealing factors, which in effect contribute to all levels of gene expression, ribonucleoprotein assembly and RNA-mediated regulation. Within the different processes some RNA chaperones act as accessory factors, while others are integral components of the macromolecular machineries that catalyze the different reaction pathways ${ }^{5}$. Mitochondrial transcript maturation in African trypanosomes requires an RNA editing reaction in which non-functional pre-mRNAs are converted into translatable mRNAs by the site-specific insertion and deletion of exclusively $U$-nucleotides ${ }^{6}$. Some transcripts are edited by the insertion of literally hundreds of U's, which ultimately account for more than $50 \%$ of the mRNA sequence. The reaction is catalyzed by a $0.8 \mathrm{MDa}$ mitochondrial multienzyme complex termed the editosome $\mathrm{e}^{7}$. RNA editing has been shown to involve RNA annealing factors ${ }^{8}$ as well as DEAD-box-type RNA helicases ${ }^{9-11}$, however, recent evidence suggests that the editosome also executes an RNA chaperone function ${ }^{12}$. Although the molecular details of the chaperone reaction are not understood, it has been demonstrated that it is capable of refolding pre-edited mRNAs ${ }^{12}$, which are characterized by an unusual nucleotide bias. Especially all substantially i.e. pan-edited pre-mRNAs are extremely purine-rich with in some cases purine/pyrimidine (R/Y) ratios $>2.5$ (Supplementary Table 1).

By monitoring the local dynamic of $>7200$ nucleotides in several pre-edited mRNAs in their free and editosome-bound folding states we uncovered that the RNA chaperone activity of the T. brucei editosome acts by raising the dynamic of bound substrate RNAs. The reaction shows a preponderance for U-nucleotides and thus provides a first rational for the inexplicable U-specificity of the RNA editing reaction.

\section{Results}

Pre-edited mRNAs adopt thermodynamically highly stable 2D-structures. To map changes in the structural landscape of pre-edited mRNAs upon binding to editosomes we used the SHAPE (selective 2' -hydroxyl 
A

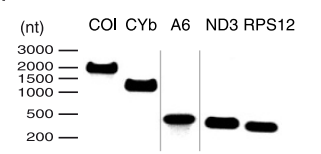

B

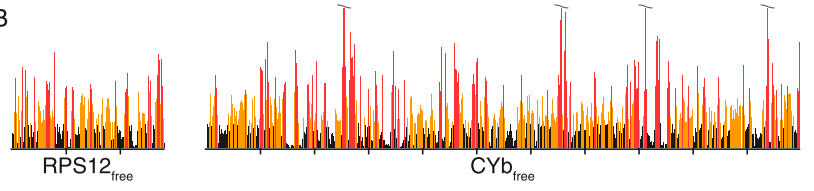

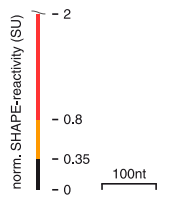
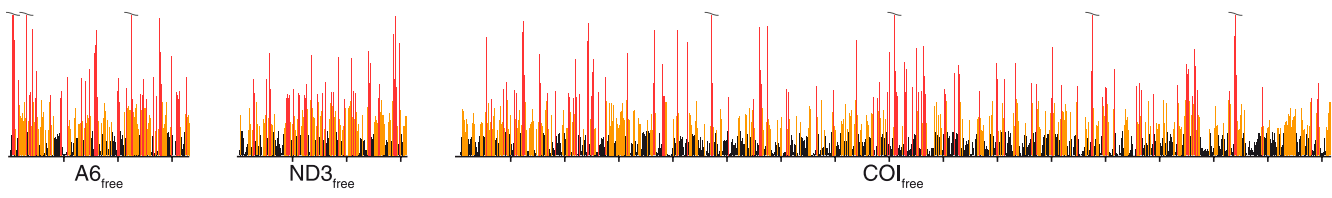

C
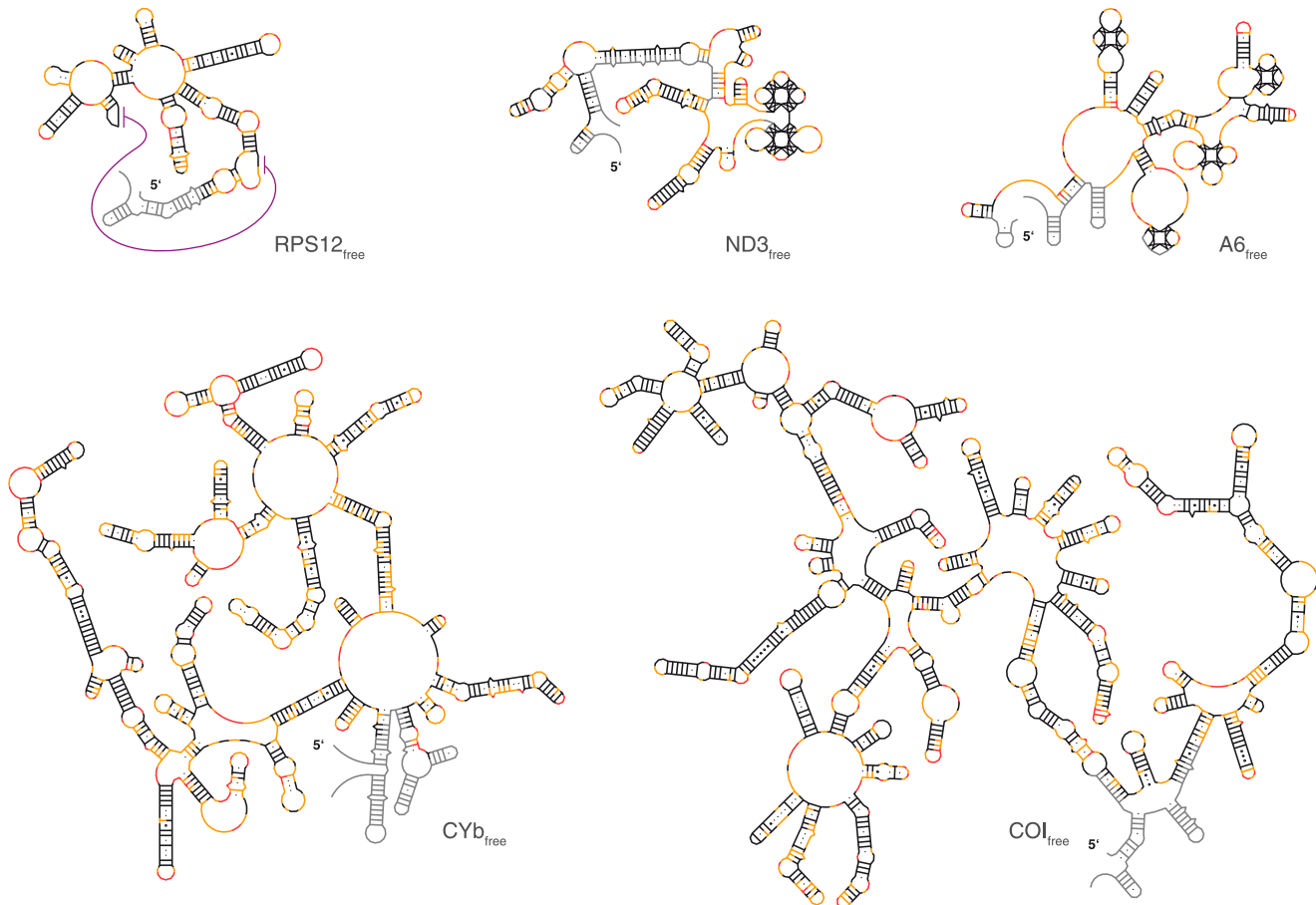

Figure 1. SHAPE-derived 2D-structures of T. brucei mitochondrial pre-mRNAs in their free folding states. (A) Gel electrophoretic characterization of the T. brucei COI-, CYb-, A6-, ND3- and RPS12-transcripts. (B) Normalized SHAPE-reactivity profiles of all 5 transcripts as free RNAs. Black: low $(<0.35 \mathrm{SU})$; yellow: medium $(0.35 \leq \mathrm{SU}<0.8)$; red: high $(\geq 0.8 \mathrm{SU})$ normalized SHAPE-reactivities. SU: SHAPE-unit. nt: nucleotides. A representative example of the individual steps to generate normalized SHAPE-profiles is given in Supplementary Fig. 2. (C) SHAPE-derived MFE-2D-structures of the 5 transcripts in their free folding states (coloring scheme as above). Purple line: pseudoknot fold in the RPS12-transcript. Grey: plasmid-derived $5^{\prime}$ - and $3^{\prime}$-nt extensions or no data.

acylation analyzed by primer extension) chemical probing method developed by Weeks et al. ${ }^{13-15}$. SHAPE provides quantitative structural information with single-nucleotide resolution based on the accessibility of $2^{\prime}-\mathrm{OH}$ groups of conformationally flexible ribonucleotides to electrophilic acylation reagents. For the analysis we used 5 mitochondrial transcripts: the pre-mRNA of ribosomal protein S12 (RPS12), the transcript of subunit 3 of the NADH dehydrogenase (ND3), the pre-mRNAs of subunit 6 of the mitochondrial ATPase (A6) and of apocytochrome $\mathrm{b}(\mathrm{CYb})$ and the transcript of cytochrome oxidase I (COI). The different RNAs range in size from 282 nucleotides to 1647 nucleotides and include pre-mRNAs that are pan-edited (A6, ND3, RPS12), only marginally edited $(\mathrm{CYb})$ and never-edited (COI). All RNAs were generated by run off in vitro transcription from linearized plasmid DNA constructs (Fig. 1A) and were refolded at native $\mathrm{pH}$ and ion conditions. Structure probing was performed using the electrophile 1-methyl-7-nitroisatoic anhydride (1M7). 1M7 is a fast reacting compound with a half-life of $14 \mathrm{sec}^{16}$. The acylation is self-limiting due to hydrolysis of the reagent and has been shown to be insensitive to solvent accessibility constraints ${ }^{17}$.

Figure 1B shows representative, normalized SHAPE-profiles for all 5 pre-mRNAs. Depending on the transcript up to 8 independent experiments were performed yielding Pearson correlation coefficients $(r)$ of up to $0.87 \pm 0.04$ (Supplementary Fig. 1). Altogether $>3600$ SHAPE-data points were generated. The individual reactivities were converted into pseudo Gibbs free energy terms $\left(\Delta \mathrm{G}_{\mathrm{SHAPE}}\right)$ to calculate experimentally derived minimal free energy (MFE) 2D-structures as shown in Fig. 1C. All pre-mRNAs adopt highly complex 2D-folds with $\Delta \Delta \mathrm{G}$ 's of $-823 \mathrm{kcal} / \mathrm{mol}(\mathrm{COI}),-496 \mathrm{kcal} / \mathrm{mol}(\mathrm{CYb}),-152 \mathrm{kcal} / \mathrm{mol}(\mathrm{RPS} 12),-137 \mathrm{kcal} / \mathrm{mol}(\mathrm{ND} 3)$ and 


\begin{tabular}{|c|c|c|c|c|c|c|}
\hline & & & & e-mRNA & & \\
\hline & & RPS12 & $\mathrm{ND}_{\mathrm{pe}}$ & $\mathbf{A 6}_{\mathrm{pe}}$ & $\mathrm{CYb}_{\mathrm{me}}$ & $\mathrm{COI}_{\mathrm{ne}}$ \\
\hline & $\Delta \mathrm{G}_{\mathrm{RNAStructure}}$ & -102 & -98 & -98 & -344 & -468 \\
\hline In silico & $\Delta \mathrm{G}_{\text {ViennaRNA }}$ & -103 & -107 & -107 & -336 & -459 \\
\hline & $\Delta \mathrm{G}_{\mathrm{SHAPE}}$ & -152 & -137 & -137 & -496 & -823 \\
\hline RNA & $\Delta \mathrm{G} / \mathrm{nt}$ & -0.45 & -0.37 & -0.34 & -0.41 & -0.48 \\
\hline $\mathrm{KNA}_{\text {free }}$ & $\Delta \mathrm{G} / \mathrm{bp}$ & -1.46 & -1.35 & -1.59 & -1.27 & -1.47 \\
\hline & $\mathrm{r}\left(\mathrm{nt}_{\mathrm{bp}} / \mathrm{nt}_{\mathrm{ss}}\right)$ & 0.62 & 0.57 & 0.47 & 0.64 & 0.66 \\
\hline & $\Delta \mathrm{G}_{\mathrm{SHAPE}}$ & -127 & -124 & -113 & -407 & -725 \\
\hline & $\Delta \mathrm{G} / \mathrm{nt}$ & -0.38 & -0.33 & -0.28 & -0.33 & -0.43 \\
\hline & $\Delta \mathrm{G} / \mathrm{bp}$ & -1.39 & -1.23 & -1.62 & -1.09 & -1.39 \\
\hline & $\mathrm{r}\left(\mathrm{nt}_{\mathrm{bp}} / \mathrm{nt}_{\mathrm{ss}}\right)$ & 0.54 & 0.55 & 0.37 & 0.61 & 0.61 \\
\hline $\mathrm{RNA}_{\text {ed.-bound }}$ & $\Delta \Delta \mathrm{G}$ & 25 & 14 & 23 & 89 & 98 \\
\hline & $\Delta \Delta \mathrm{G} / \mathrm{nt}$ & 0.08 & 0.04 & 0.06 & 0.07 & 0.06 \\
\hline & $\Delta \Delta \mathrm{G} / \mathrm{bp}$ & 0.07 & 0.12 & -0.03 & 0.17 & 0.08 \\
\hline & $\Delta \mathrm{nt}_{\text {basepaired }}(\%)$ & -7.7 & -2.7 & -10.1 & -3.1 & -4.5 \\
\hline & bp preserved (\%) & 84 & 82 & 50 & 55 & 52 \\
\hline
\end{tabular}

Table 1. Summary of the thermodynamic folding characteristics of mitochondrial pre-mRNAs in their free and editosome-bound RNA folding state. $\Delta \mathrm{G}$-values are in $\mathrm{kcal} / \mathrm{mol}$. pe: pan-edited, me: marginally edited, ne: never edited.

$-137 \mathrm{kcal} / \mathrm{mol}$ (A6). These values calculate to $\Delta \mathrm{G} / \mathrm{nt}$-values between $-0.34 \mathrm{kcal} / \mathrm{mol}$ and $-0.48 \mathrm{kcal} / \mathrm{mol}$ and $\Delta \mathrm{G} / \mathrm{bp}$-values between $-1.27 \mathrm{kcal} / \mathrm{mol}$ and $-1.59 \mathrm{kcal} / \mathrm{mol}$ (Table 1 ). In order to verify these values we performed temperature-dependent UV-hyperchromicity measurements and compared the measured hyperchromicities to the expected values of the SHAPE-derived 2D-structures (Supplementary Fig. 3). On average the two data sets differ only by $15 \%$ and thus corroborate the complex folds of the different transcripts. Importantly, nearest neighbor-based $2 \mathrm{D}$-folding predictions $\mathrm{s}^{18,19}$ underestimate the experimentally derived thermodynamic stabilities on average by $30 \%$ (Table 1 ) emphasizing the need for structure probing experiments. Almost all known RNA $2 \mathrm{D}$-structure features can be found in the 5 transcripts including a high number of G/U basepairs and a pseudoknot in the pre-mRNA of RPS12 (summarized in Supplementary Table 2).

Pre-edited A6 and ND3 transcripts contain multiple GQ-elements. One of the identified RNA folding features in the different pre-edited transcripts is of special interest: In two of the pre-mRNAs we identified multiple G-quadruplex (GQ)-folds ${ }^{20,21}$. GQ-elements represents the most stable structures in DNA and RNA. The 2D-structure of the A6-transcript contains four and the ND3-transcript contains two GQ-folds (Fig. 1C). In order to derive an additional experimental verification of the GQ-elements we measured UV-thermal difference spectra $(\mathrm{TDS})^{22,23}$. TD-spectra represent the arithmetic difference between a high- and low-temperature UV-absorbance spectrum i.e between RNA in its unfolded and fully folded states. In the presence of stabilizing $\mathrm{K}^{+}$-ions, GQ-folds have been shown to display a set of signature peaks $(243 \mathrm{~nm}, 273 \mathrm{~nm} \text { and } 295 \mathrm{~nm})^{23}$ and Fig. 2 shows representative TD-spectra for both, the A6 and ND3 transcripts. The two pre-mRNAs are characterized by all GQ-specific minima and maxima, which disappear in the presence of destabilizing $\mathrm{Na}^{+}$- and $\mathrm{Li}^{+}$-ions. The exact positions of the different GQ's were identified in premature reverse transcriptase (RT) termination assays ${ }^{24,25}$. As shown in Fig. 3, at $75 \mathrm{mM} \mathrm{K}^{+}$all G-nucleotide containing sequences involved in the formation of the individual GQ's were identified as strong RT-stop signals.

Editosome binding increases the dynamic of pre-edited mRNAs. Next we probed the structures of the selected pre-mRNAs in their editosome-bound folding state. For that we preincubated the transcripts with active editosomes in a 1:1 molar stoichiometry. Binding equilibrium was achieved at $27^{\circ} \mathrm{C}$ for $45-60 \mathrm{~min}$. Per RNA between 3 and 7 independent SHAPE-experiments were performed ultimately generating 3614 data points ( $r$ up to $0.81 \pm 0.07$; Supplementary Fig. 1 ). As before, normalized SHAPE-reactivity profiles were plotted (Supplementary Fig. 4) to calculate experimentally-derived MFE-2D-structures for the 5 pre-mRNAs in their editosome-bound folding state. Importantly, in their bound form, all transcripts adopt less stable 2D-folds with on average $15 \%$ reduced Gibbs free energies $(\Delta \Delta$ G's) (Table 1). Based on the specificity of the acylation reagent this indicates a change in the folding landscape to increase the flexibility of the different pre-mRNAs. Figure $4 \mathrm{~A}$ shows $\triangle$ SHAPE-profiles of all pre-mRNAs highlighting the reactivity differences (increases/decreases) between the two folding states (free $v s$. editosome-bound). In spite of the different sizes of the transcripts the data demonstrate a global increase in reactivity especially for all edited transcripts. Reactivity differences generally spread throughout the entire primary sequences with individual nucleotides showing hyperreactive characteristics $(>|2 \mathrm{SU}|)^{17}$. A quantitative comparison of the reactivity differences is given in Fig. 4B. While the never-edited COI transcript is only marginally affected $(0.01 \mathrm{SU})$, all edited transcripts (RPS12, A6, ND3, CYb) show net reactivity increases between $0.05-0.22 \mathrm{SU}$. The same picture can be drawn from the arithmetic mean (AM) of the normalized SHAPE-reactivities (Supplementary Fig. 5). On average 29\% of the nucleotide positions in every pre-mRNA are affected in the conformational transition (Fig. 4C). Furthermore, by analyzing the correlation between nucleotide identity and changes in SHAPE-reactivity, we identified that U-nucleotides represent the most responsive 

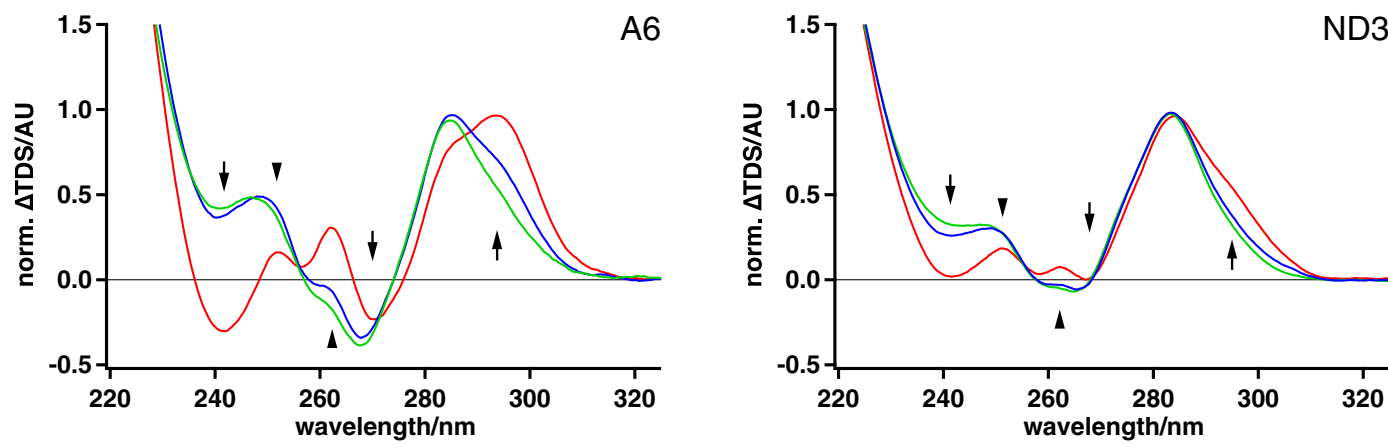

Figure 2. Experimental verification of GQ-folds - thermal difference (TD) spectra. Normalized doubledifference TD-spectra of the A6- and ND3-transcript in the presence of $\mathrm{KCl}$ (red), $\mathrm{NaCl}$ (blue) and $\mathrm{LiCl}$ (green). Signature peaks of GQ-folds are marked by arrows ${ }^{23}$. Additional differences are indicated by arrowheads. AU: arbitrary unit. Peak intensities decrease in the presence of GQ-destabilizing $\mathrm{Na}^{+}$- and $\mathrm{Li}^{+}$-ions.

nucleotides in the folding transition (Supplementary Fig. 6). From a total of 93 nucleotide positions that undergo a conversion from $<0.35 \mathrm{SU}$ to $>0.8 \mathrm{SU} 66$ nucleotides or $71 \%$ are U-residues. Considering the nt-bias in the different pre-mRNAs and by plotting the ratio of observed/expected SHAPE-reactivities, the U-specificity of the chaperone activity becomes strikingly obvious. (Fig. 4D). This demonstrates that the RNA folding landscape of all 5 transcripts is simplified by increasing the flexibility of primarily U's.

Figure 5A shows the SHAPE-derived MFE-2D-structures of the 5 RNAs in their editosome-bound form highlighting the $10 \%$ most responsive nucleotide positions. Compared to the free RNA folding states the average $\Delta \mathrm{G} / \mathrm{nt}$-value of the 5 transcripts drops from $-0.41 \mathrm{kcal} / \mathrm{mol}$ to $-0.33 \mathrm{kcal} / \mathrm{mol}$ and the mean $\Delta \mathrm{G} / \mathrm{bp}$-value decreases from $-1.43 \mathrm{kcal} / \mathrm{mol}$ to $-1.34 \mathrm{kcal} / \mathrm{mol}$ (Table 1). Two GQ-elements in the A6 transcript and one GQ-fold in the ND3 transcript no longer exist, demonstrating that the editosome chaperone activity possesses GQ-resolving potency analogous to the RecQ and Pif1-families of helicase ${ }^{20}$. Similarly, the pseudoknot in the RPS12 transcript is absent in the edititosome-bound folding state. Figure 5B illustrates the 2D-folds and structural changes in a "circle plot" representation ${ }^{26}$. On average $65 \%$ of all basepairs in the free RNAs are preserved in the editosome-bound conformations. Roughly $20 \%$ of the basepairs are exclusive to either of the two folding states and the basepairing-content of all editosome-bound RNA structures is invariably lower than in the free RNA folding state (maximally $10 \%$ ).

The editosome-bound folding state favors the formation of pre-mRNA/gRNA hybrid RNAs. The mechanistic rational for increasing the flexibility of editosome-bound RNAs is to overcome the structural rigidity of the different pre-edited transcripts to lower the energy barrier for subsequent steps in the editing cycle. Based on our current knowledge, the next step in the reaction is the annealing of a gRNA molecule to generate a pre-mRNA/gRNA hybrid, which defines the pre-mRNA endonucleolytic cleavage site for the U-insertion/deletion reaction. As a consequence of the data above, the formation of gRNA/pre-mRNA hybrid RNAs should be thermodynamically favored if the pre-mRNA is in its "flexible" i.e. editosome-bound state and disfavored if the transcript is in its "rigid" (free) configuration. To experimentally falsify this hypothesis we developed an assay in which the formation of pre-mRNA/gRNA hybrid is mimicked by short DNA-oligonucleotides as "guiding" molecules. This enabled us to quantitatively assess hybrid formation by RNaseH cleavage. Representative results are shown in Fig. 6 using CYb as a target pre-mRNA. Invariably, hybrid formation is favored if the transcript is in the editosome-bound folding state and not in the free RNA conformation. Depending on the guiding DNA-oligonucleotide up to 5-fold differences were measured between the two folding states, which demonstrates that at least one function of the editosome chaperone activity is to alter the pre-mRNA folding landscape to promote the formation of gRNA/pre-mRNA hybrid RNAs.

\section{Discussion}

Mitochondrial gene expression in African trypanosomes requires RNA editing. By inserting and deleting only U-nucleotides, the processing reaction converts non-functional, pre-edited transcripts into translation-competent mRNAs. Editing follows a multistep catalytic reaction cycle that is mediated by a mitochondria-specific, high molecular mass protein particle known as the editosome ${ }^{7}$. Editosomes are characterized by a single RNA interaction domain on their surface ${ }^{12}$ and the binding of pre-edited mRNAs as substrates in the process has been shown to involve a chaperone-type RNA refolding reaction ${ }^{12}$. Unfortunately, the biochemical and structural details of the chaperoning process are not understood. Here we aimed at characterizing the editosome-inherent RNA chaperone activity by monitoring the folding transitions of 5 pre-edited mRNAs from their free folding state to their editosome-bound conformation using site-specific chemical probing ${ }^{13-15}$. We demonstrate that the pre-edited mRNAs in their free state adopt strikingly elaborate RNA folding characteristics with thermodynamic stabilities resembling structural RNAs. Two of the tested transcripts (A6, ND3) even contain multiple, up to 4 G-quadruplex elements, which represent the most stable folding motifs in DNA and RNA ${ }^{20}$. However, editosome binding changes the structures of the different transcripts by simplifying their folding landscapes through an increase in RNA dynamic. About 30\% of the nucleotide positions in every RNA are involved in the folding transition and invariably, the resulting editosome-bound MFE-structures have reduced thermodynamic stabilities. 

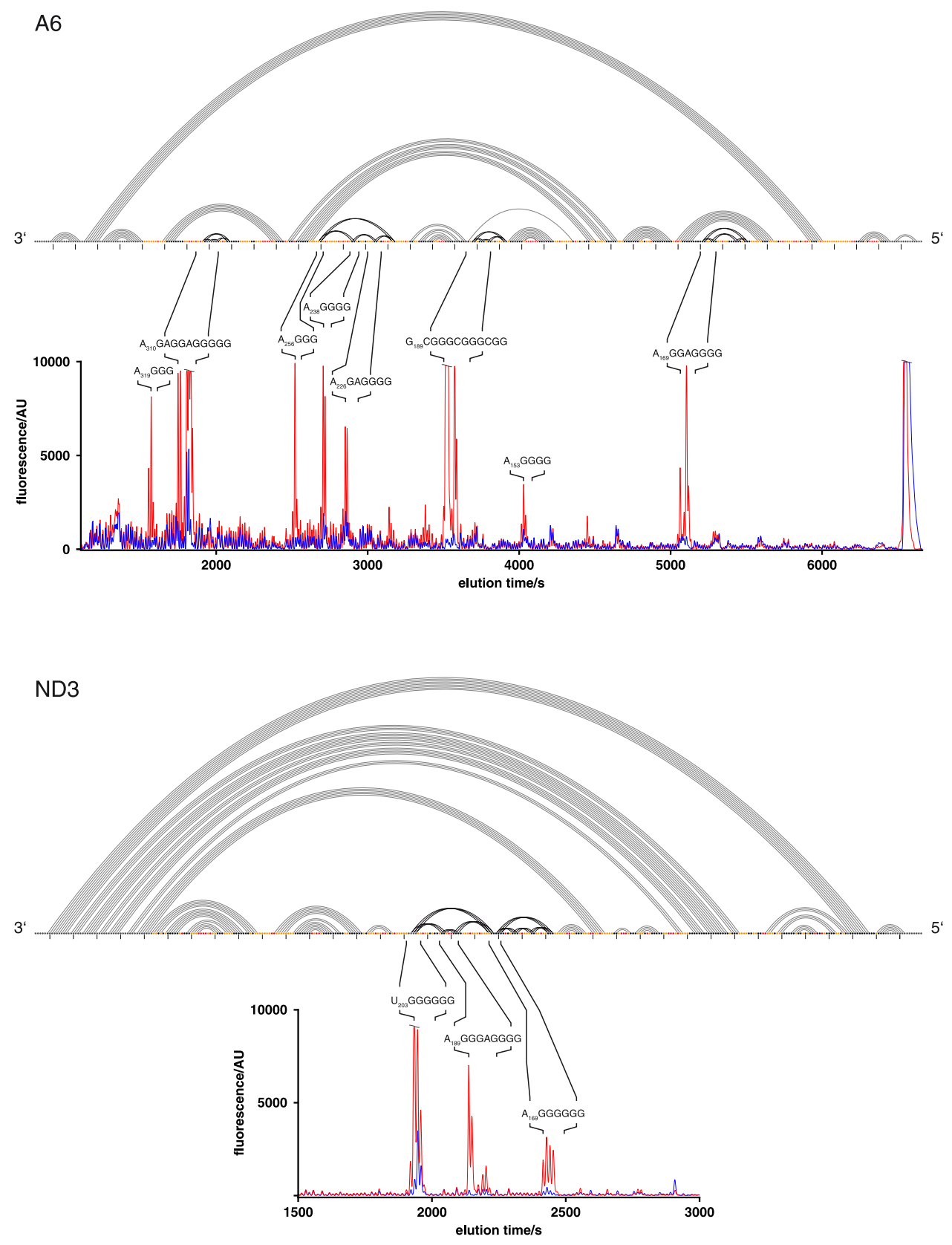

Figure 3. Experimental verification of GQ-folds - RT-stop assays. Capillary electrophoretic (CE)-traces of premature reverse transcriptase (RT)-stop assays of the A6- and ND3-transcripts in the presence of GQ-stabilizing $\mathrm{K}^{+}$-ions (red) and GQ-destabilizing $\mathrm{Na}^{+}$-ions (blue). Sequence identities of the individual RT-stop signals are shown on top of the different peaks. RNA secondary structures are annotated as arcs above the CE-traces. AU: arbitrary unit.

Although the different RNAs are not completely unfolded at the tested 1:1 editosome/pre-mRNA stoichiometry, fifty percent of the GQ-structures no longer exist in the editosome-bound RNA conformation. Importantly, the increase in RNA dynamic has a direct consequence for the editing reaction cycle and thus provides a rational for the chaperone function. Rate limiting step of the reaction is the binding of gRNA molecules to form short, intermolecular gRNA/pre-mRNA hybrid structures. These hybrid elements define the endonucleolytic cleavage sites within the pre-mRNA molecules, which represents the first step in the reaction cycle. The formation of gRNA/pre-mRNA hybrid RNAs has been shown to involve matchmaking-type RNA/RNA annealing factors ${ }^{8}$, however, the data above demonstrate that the editosome itself contributes to the formation of hybrid RNAs. By increasing the dynamic of bound pre-mRNAs, the activity raises the probability for a gRNA to anneal to its base-complementary target site, thereby initiating the reaction cycle.

Interestingly, the RNA folding landscape of the pre-edited mRNAs is altered by specifically increasing the dynamic of preferentially U-nucleotides in the different transcripts. This nucleotide specificity finds precedence in the RNA chaperone mechanism of the retroviral NC and hnRNP A1 proteins, which have been shown to 
A<smiles>C#CCC(C)CC#C</smiles><smiles>NC1CCCC1</smiles>

A6

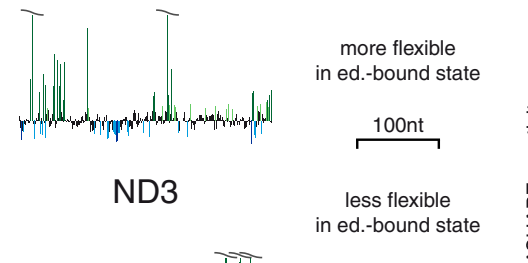

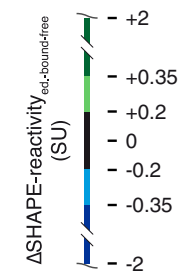
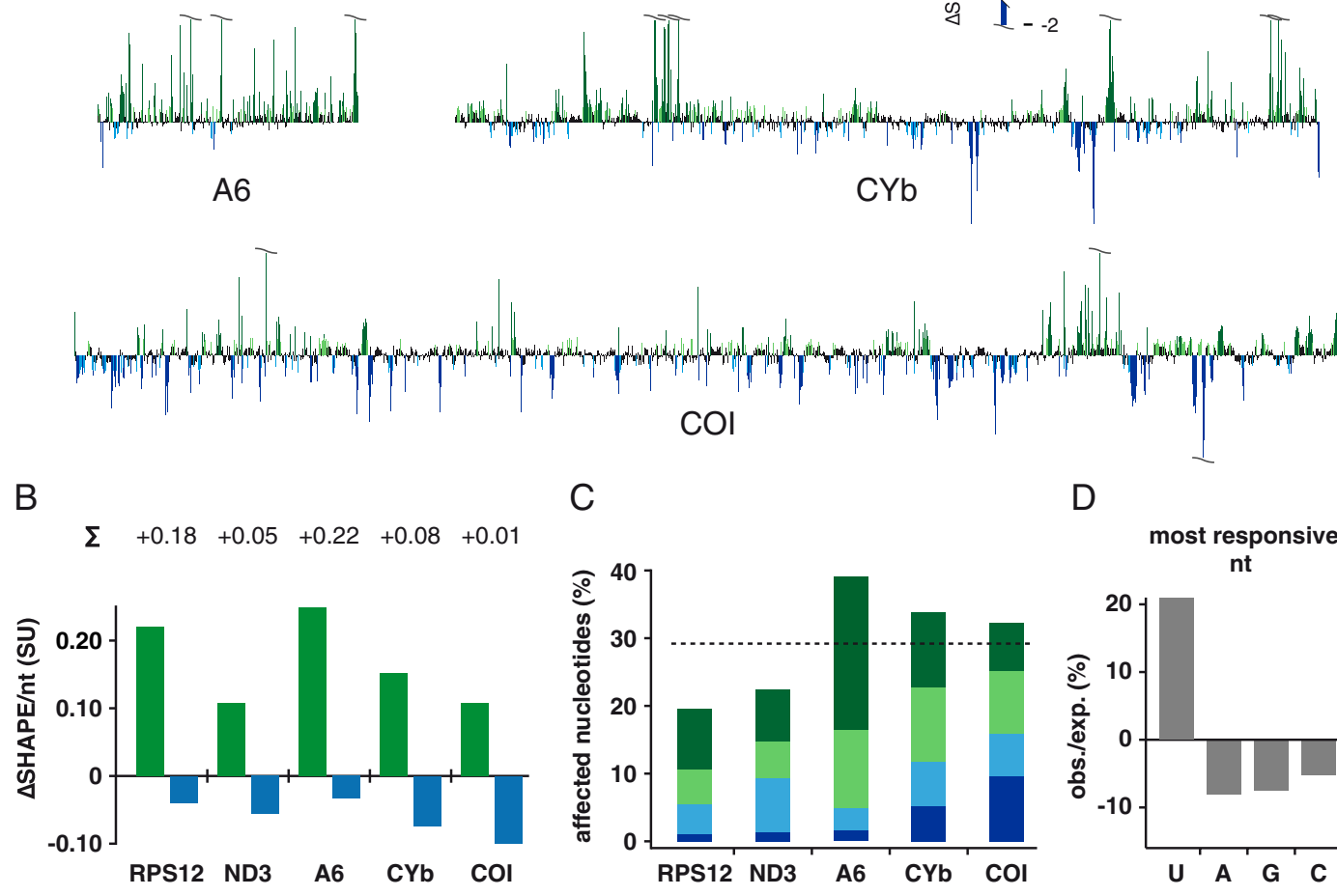

C

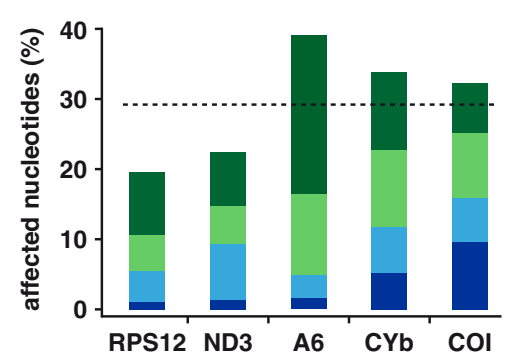

D

most responsive nt

Figure 4. SHAPE-reactivity changes in the editosome-bound folding state. (A) Difference $(\Delta)$ SHAPE-reactivity profiles of the RPS12-, ND3-, A6-, CYb- and COI-transcripts. Green: nt-positions with increased SHAPE-reactivities in the editosome-bound folding state (dark green: $+0.35 \leq \mathrm{SU} \leq+2$; light green: $+0.2 \leq \mathrm{SU}<+0.35)$. Blue: nt-positions with decreased SHAPE-reactivities in the editosome-bound folding state (light blue: $-0.2 \geq \mathrm{SU}>-0.35$; dark blue: $-0.35 \geq \mathrm{SU} \geq-2$. Black: non-responsive nt-positions $(-0.2 \leq \mathrm{SU} \leq+0.2)$. (B) Bar graph summing up all increased (green) and decreased (blue) $\triangle \mathrm{SHAPE}$ reactivities. Numbers represent the difference of the two values and demonstrate a general increase in ntflexibility upon editosome binding. SU: SHAPE-unit. nt: nucleotides. (C) Bar graph illustrating the percentage of affected nucleotides in all 5 transcripts. Stippled line: Arithmetic mean. (D) Bar graph illustrating the under-/ over-representation of SHAPE-responsive nucleotides in the editosome-bound folding state. Values were calculated by determining the fraction of all 4 ribonucleotides $(\mathrm{A}, \mathrm{G}, \mathrm{C}, \mathrm{U})$ within the top $10 \%$ of responsive positions in the 5 transcripts divided by the relative abundance of each nt in that interval.

execute a G-centric refolding activity ${ }^{4}$. U-nucleotides represent promiscuous base-pairing partners ${ }^{27}$. They form homo- and hetero-basepairs with all other ribonucleotides and thus we propose that the U-specificity is a consequence of a selection process to globally lower the basepairing probability of pre-mRNAs by raising the dynamic of predominantly U's. This assures that the highest number of possible basepairs is affected. As a consequence, it is tempting to speculate that this might represent the driving force for the enigmatic U-specificity of the RNA editing process as a whole. The unfolding reaction should thermodynamically and perhaps kinetically "accelerate" as the editing reaction proceeds since the $\mathrm{U}$-content dramatically increases (especially for all pan-edited mRNAs). Furthermore, the $\mathrm{U}$-centricity might also explain why editing involves roughly 10 -times more $\mathrm{U}$-insertions than U-deletions ${ }^{6}$.

The data also suggest that the editosome does not discriminate between folded and misfolded RNAs or between transcripts that undergo editing or are never edited. COI-RNA as a never-edited transcript, behaved qualitatively and quantitatively identical to all other RNAs. This indicates that the difference between a productive and non-productive chaperone reaction is simply the probability increase in forming a gRA/pre-mRNA hybrid, which drives the reaction towards the next step in the editing cycle. Which of the protein components of the editosome executes the chaperone activity is not known to date. It has been suggested that the activity resides within the different OB-fold proteins of the complex ${ }^{12}$ based on the observation that the yeast Rrp44 polypeptide executes an OB-fold-driven RNA chaperone activity ${ }^{28,29}$. Importantly, since $1 \mathrm{M} 7$ does not probe solvent accessibility ${ }^{17}$ no conclusion as to the contact site(s) of the different transcripts with the editosome can be made. However, we predict that the catalytic complex displays a surface domain that is highly disordered and flexible ${ }^{30}$, which enables it to interact with a diverse landscape of RNAs of different length and 3D-conformations. This 
A

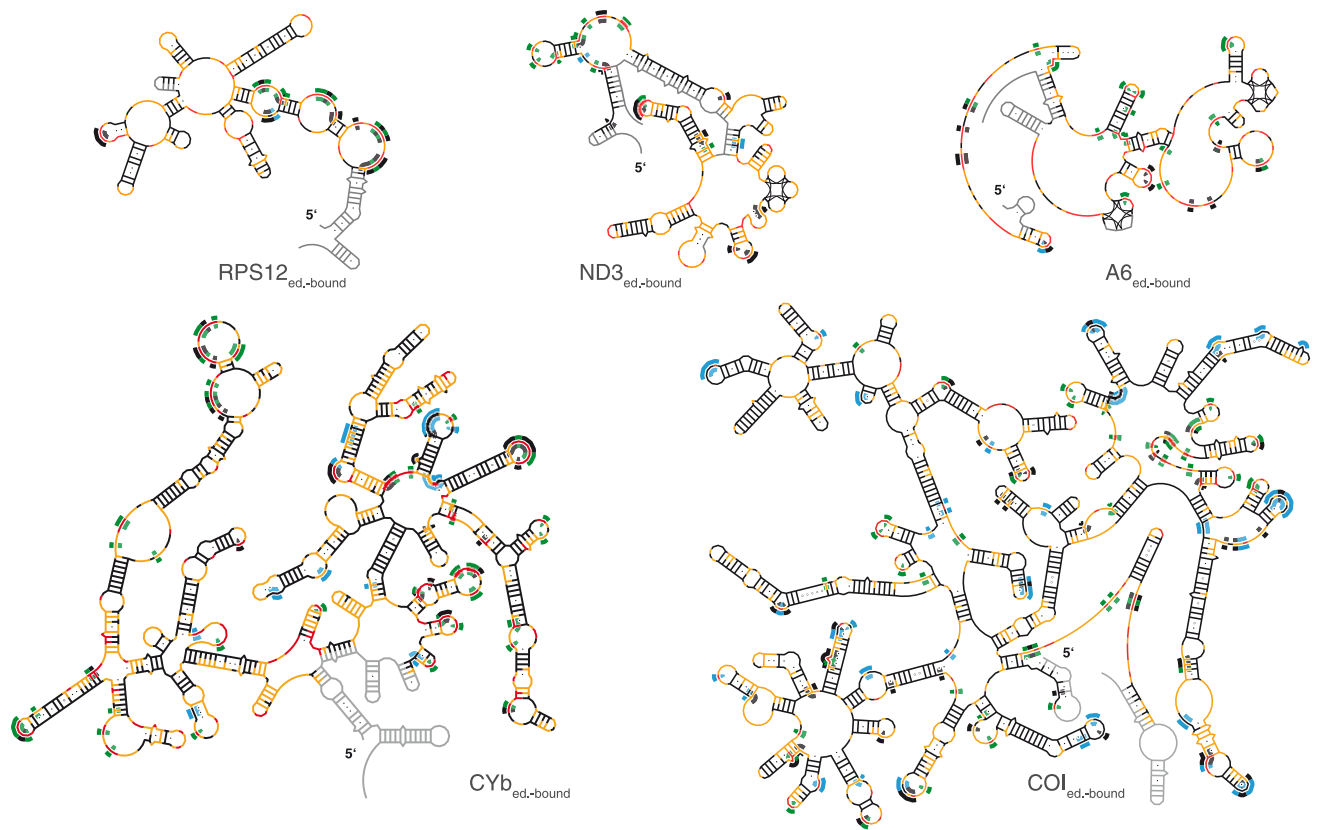

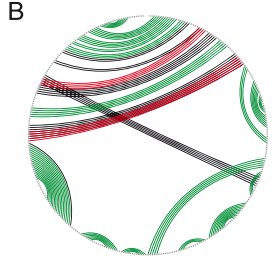

RPS12

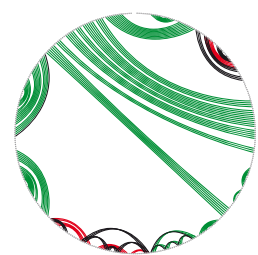

ND3

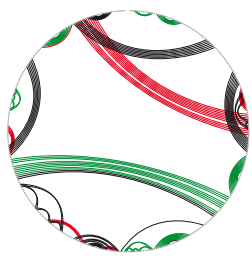

A6

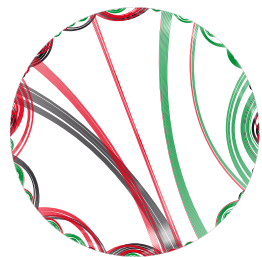

$\mathrm{CYb}$

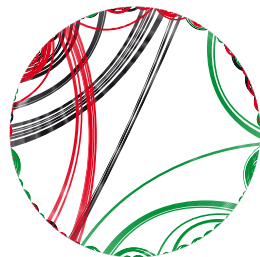

$\mathrm{COI}$

Figure 5. Mapping the structural transition from free RNA to editosome-bound RNA. (A) SHAPEderived MFE-2D-structures of all 5 transcripts in their editosome-bound conformation. U-nt within the top $10 \%$ of responsive nt-positions are shown in green (increased SHAPE-reactivity) and blue (decreased SHAPE-reactivity). Black: non-uridine responsive nt. (B) Circle plot representations of the SHAPE-derived 2D-structures of the 5 pre-mRNAs. Base pairs are shown as colored lines. Green: basepairs present in both RNA folding states. Red: basepairs unique to the editosome-bound RNA conformations. Black: basepairs unique to the free RNA folding states. Plots were generated using CircleCompare of RNAstructure ${ }^{26}$.

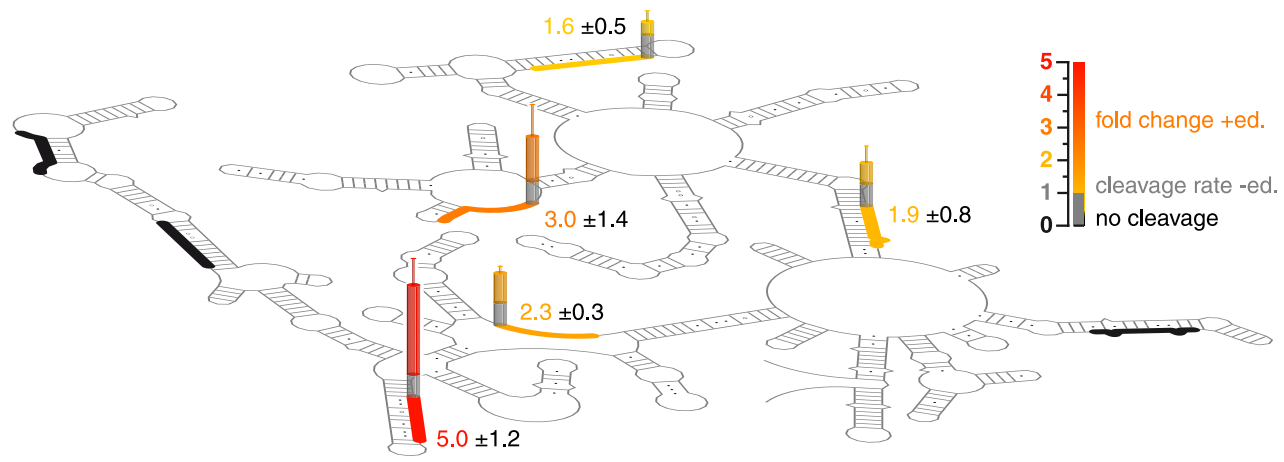

Figure 6. Guide RNA/pre-mRNA-hybrid formation in the free and editosome-bound RNA folding states. Background: SHAPE-derived 2D-fold of the CYb pre-mRNA. The binding sites of eight base-complementary DNA-oligonucleotides acting as quasi gRNAs are shown as thick lines. Colored bars indicate the change in RNaseH-based cleavage of the different DNA/pre-mRNA-hybrid molecules in the free and editosome-bound RNA folding states. Grey: RNaseH-cleavage in the free RNA folding state $(=1)$. Yellow-red: $>1-5$-fold stimulus in the editosome-bound folding state. Black: no RNaseH cleavage. Errors are standard deviations (SD). A representative example of the data acquisition, normalization and quantification procedures is shown in Supplementary Fig. 8. 
flexibility is likely central to the chaperone activity because it allows the editosome to remain in contact with RNA as it is remodeled and edited ${ }^{3,31}$.

This is the first time that a dynamic reaction step of the RNA editing reaction cycle has been demonstrated experimentally. The editosome amplifies the intrinsic dynamic behavior of bound substrate RNAs ${ }^{32}$ and induces multiple, U-specific RNA-equilibrium motions $\mathrm{s}^{33-35}$ to counteract the high thermodynamic stabilities of pre-edited mRNAs. This U-nucleotide centricity provides a first physicochemical rational for the perplexing U-specificity of the editing reaction.

\section{Methods}

Cloning and RNA synthesis. Mitochondrial genes encoding subunit 6 of the mitochondrial ATPase (A6), apocytochrome b (CYb), NADH dehydrogenase subunit 3 (ND3), ribosomal protein S12 (RPS12) and cytochrome c oxidase subunit I (COI) were PCR-amplified from T. brucei Lister 427 genomic $\mathrm{DNA}^{36}$ using the following DNA-oligonucleotide primers (KpnI and SacI restriction endonuclease recognition/cleavage sites are underlined): A6_forw. GGGGTACC-AGAGGAATTTTGGGCGGAA-GAG; A6_rev. CCGAGCTCCTATAACTCCAAAATCACAACTTTC; COI_forw. GGGGTACCATGTTTTTTCTATGTCTTGTGTGC; COI_rev. CCGAGCTCTATAT-AAAAGAATAATAGGAAGG; CYb_forw. GGGGTACCAGCGGAGAAAAAAG-AAAGGGTC; CYb_rev. CCGAGCTCCTAATCTAACCTACACACTATG; ND3_forw. GGGG TACCTCAAA A A A - T C T C GC T T T T TACT T TAG; N D _rev. CCGAGCTCCT TGATGTTAGTAT-AAATGATTATATG; RPS12_forw. GGGGTACCCTAATACACTTTTGATAACAA-ACTAAAG; RPS12_rev. CCGAGCT-CCCTACCAAACATAAATGA-ACCTG. PCR-amplicons were cloned into the KpnI and SacI sites of phagemid pBS SK- (Invitrogen) and transcripts were generated by run off in vitro transcription from linearized plasmids using T7-RNA polymerase. RNAs were purified from non-incorporated NTP's by size exclusion chromatography, EtOH-precipitated and dissolved in $10 \mathrm{mMTris} / \mathrm{HCl} \mathrm{pH} \mathrm{7.5,} 1$ mM EDTA (TE).

Editosome preparations. Editosomes were isolated from insect stage Trypanosoma brucei using the monomorphic strain Lister $427^{36}$. Cells were grown in SDM79-medium ${ }^{37}$ to a cell density of $1 \times 10^{7}$ cells $/ \mathrm{mL}$. After harvesting cells were disrupted by $\mathrm{N}_{2}$-cavitation at isotonic conditions ${ }^{38}$. Mitochondrial vesicles were separated in Percoll step gradients and lysed in 1\% (v/v) Nonidet P-40 in editing buffer (EB: $20 \mathrm{mM} \mathrm{HEPES/KOH,} \mathrm{pH} 7.5$, $30 \mathrm{mM} \mathrm{KCl}, 10 \mathrm{mM} \mathrm{Mg}(\mathrm{OAc})_{2}, 1 \mathrm{mM}$ DTT) containing $1 \mathrm{mM}$ PMSF, $1 \mu \mathrm{g} / \mathrm{mL}$ leupeptin and $10 \mu \mathrm{g} / \mathrm{mL}$ trypsin inhibitor. The detergent lysates were further separated by isokinetic ultracentrifugation in 10-35\% (v/v) linear glycerol gradients as in Göringer et al., $1994^{39}$ and after fractionation, $20 \mathrm{~S}$ fractions were assayed for their RNA editing $^{40,41}$ (Supplementary Fig. 7) and RNA binding activity ${ }^{42}$. RNA binding and RNA editing-competent fractions were stored at $-20^{\circ} \mathrm{C}$.

SHAPE-modification. The modification reagent 1-methyl-7-nitroisatoic anhydride (1M7) was synthesized as described ${ }^{43}$. Mitochondrial pre-mRNAs $(0.1 \mu \mathrm{M})$ were denatured by heating to $95^{\circ} \mathrm{C}(2 \mathrm{~min})$ followed by snap cooling on ice. RNA refolding was achieved by equilibration in $\mathrm{EB}$ for $30 \mathrm{~min}$ at $27^{\circ} \mathrm{C}$, which represents the optimal growth temperature of insect-stage trypanosomes. RNA samples were split and treated either with $3.5 \mathrm{mM} 1 \mathrm{M} 7$ in DMSO or the same volume of neat DMSO. Modification reactions were quenched after $70 \mathrm{sec}$ by the addition of an equal volume of $\mathrm{ddH}_{2} \mathrm{O}$. RNAs were recovered by EtOH precipitation and desalted by size exclusion chromatography. 1M7-modifications in presence of $20 \mathrm{~S}$ editosomes were performed at a molar pre-mRNA:editosome ratio of 1:1. Editosome/pre-mRNA complexes were incubated at $27^{\circ} \mathrm{C}$ for $45-60 \mathrm{~min}$ and modified RNA was recovered by phenol extraction followed by EtOH precipitation and desalting by size exclusion chromatography.

Reverse transcription and data processing. Equimolar amounts of fluorescently labeled DNA oligonucleotide primers (see below) were annealed to $1 \mathrm{M} 7$-modified or unmodified RNA samples in $0.25 \mathrm{xTE}$ $\mathrm{pH} 7.5$ by heating to $95^{\circ} \mathrm{C}(2 \mathrm{~min})$, cooling to $50^{\circ} \mathrm{C}(10 \mathrm{~min})$ and snap cooling on ice. Reverse transcription

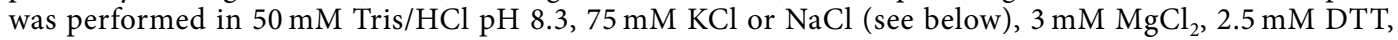
$0.25 \mathrm{mM}$ each $\mathrm{dNTP}$ and $0.75 \mathrm{U} / \mu \mathrm{L}$ RiboLock RNase inhibitor (Invitrogen). The reaction was started by prewarming the samples for $1.5 \mathrm{~min}$ prior to the addition of $5 \mathrm{U} / \mu \mathrm{L}$ SuperScript III reverse transcriptase (RT, Invitrogen). The COI- and CYb-transcripts were incubated at $52^{\circ} \mathrm{C}$ for $1 \mathrm{~h}$. The pre-mRNA for RPS 12 for $20 \mathrm{~min}$ at $40^{\circ} \mathrm{C}$ and the ND3- and A6-transcripts for $5 \mathrm{~min}$ at $50^{\circ} \mathrm{C}$ followed by $20 \mathrm{~min}$ at $55^{\circ} \mathrm{C}$. $\mathrm{K}^{+}$was used for the COI- and CYb-RNAs and $\mathrm{Na}^{+}$for the A6-, ND3- and RPS12-transcripts. Sequencing reactions were carried out using unmodified RNA, fluorescently labeled DNA oligonucleotide primer and ddNTPs at a final concentration of $0.125 \mathrm{mM}$ each. The ddNTP identity was chosen depending on the transcript analyzed. Reverse transcription was stopped by snap cooling and the addition of 0.1 vol. $4 \mathrm{M} \mathrm{NaOH}$ followed by heating to $95^{\circ} \mathrm{C}(5 \mathrm{~min})$. Samples were pooled, $\mathrm{EtOH}$ precipitated and redissolved in HiDi formamid (ABI/Life technologies) for capillary electrophoresis. Raw electrophoretic traces were analyzed using SHAPEfinder ${ }^{44}$ utilizing the boxplot approach to determine the number of statistical outliers. Normalized SHAPE-reactivities were the result of averaging a minimum of 3 independent experiments. The following $5^{\prime}$-fluorescently labeled DNA-primer molecules were used: M13_reverse: 6-FAM/JOE/6-TAMRA-CAGGAAACAGCTA-TGACCATG; T3 reverse: 6-FAM/JOE/TAMRA-AATTAACCCTCACTAAAGG-GAAC; CYb_840-818: 6-FAM/JOE/6 -TAMRA CATAAACTTATCTGGGATTGCC; CYb_603-581: 6-FAM/JOE/6-TAMRA-CCTATCAC AAAATGC-ATCAGAAC; CYb_310-282: 6-FAM/JOE/6-TAMRA-TAAATCAT-ACTAATAT ATGTGTGTCAAAC; COI_1391-1367: 6-FAM/JOE/6-TAMRA-GTCAACAAAAGCAT-ACCATACAATG; COI_1144-1123: 6-FAM/JOE/6-TAMRA-CATAGTGGAAATGTGCAACAAC; COI_1004-978: 6-FA M/JOE/6-TAMRA-CACATATCTGTGAATAAGAAGCTATAG; COI_877-857: 6-FAM/JOE/6-TAMR 
A-GATG-CGCTCAAACAAACATAC; COI_619-602: 6-FAM/JOE/6-TAMRA-CAGCCAAAACGGGAAGTG; COI_479-453: 6-FAM/JOE/6-TAMRA-CTAG-AATACCAAGAAA-ATGCACAGAG.

SHAPE-directed RNA folding. Normalized SHAPE-reactivities were used as pseudo Gibbs free energy values to guide the folding of the different pre-mRNAs using RNAstructure v5.6 ${ }^{19,45}$. In addition, ShapeKnots ${ }^{26}$ was used to search for pseudoknots using normalized SHAPE-reactivities and the default parameters of ShapeKnots $(\mathrm{p} 1=0.35 \mathrm{kcal} / \mathrm{mol} ; \mathrm{p} 2=0.65 \mathrm{kcal} / \mathrm{mol})$. To extrapolate the $\Delta \mathrm{G}$ of a pseudoknot-containing minimum free energy (MFE) structure to $27^{\circ} \mathrm{C}$ the $\Delta \Delta \mathrm{G}$ of the MFE with and without the pseudoknot at $37^{\circ} \mathrm{C}$ was added to the free energy of the MFE at $27^{\circ} \mathrm{C}$. G-quartet (GQ)-containing RNA structures were folded by initially forcing the corresponding sequence stretches into a single-stranded conformation. To estimate the $\Delta \mathrm{G}$ of the complete structure, the free energy contribution of the GQ was calculated with the help of ViennaRNA v2.1.9 ${ }^{46}$. In cases where the energy model of ViennaRNA was not applicable, the free energy of the competing, canonical 2D-structure was calculated using RNAstructure v5.6. Free energy contributions calculated by either method were finally added to the $\Delta \mathrm{G}$ of the GQ-free structure. Non-canonical and canonical basepairs were introduced based on the primary data and isolated basepairs between highly reactive nt positions were removed from the final structures. Due to the unusual high distribution of SHAPE-reactivities in the A6-pre-mRNA in its editosome-bound state, box plot-normalized and averaged peak integrals corresponding to the modified reaction of both folding states were scaled against the invariable background followed by normalization to the outlier-revised free state ${ }^{14}$.

Experimental verification of GQ-folds. GQ-structures were identified by premature RT-stop signals in the presence of GQ-stabilizing $\left(\mathrm{K}^{+}\right)$and GQ-destabilizing $\left(\mathrm{Na}^{+}\right)$ion conditions. Experiments were conducted analogous to the RT-SHAPE-procedure except that fluorescently labeled cDNAs were generated from unmodified transcripts in the presence of either $75 \mathrm{mM} \mathrm{K}^{+}$or $75 \mathrm{mM} \mathrm{Na}^{+}$. cDNA fragments were resolved by capillary electrophoresis. Nucleotide identities were determined by cDNA-sequencing.

Thermal difference spectra. Spectroscopic measurements were carried out in a thermoelectrically controlled UV-spectrophotometer in $0.5 \mathrm{~mL}$ quarts cuvettes. Prior to the analysis, RNAs were heat-denatured in $0.1 \mathrm{~mL}$ TE pH 7.5 ( $2 \mathrm{~min}$ ) and snap cooled on ice before the addition of concentrated folding buffer. Equilibration was allowed for $15 \mathrm{~min}$ and RNA concentrations were set to an initial $\mathrm{A}_{260}=1$. TD spectra were recorded in $5 \mathrm{mM}$ sodium cacodylate $\mathrm{pH} 6.8$ at $27^{\circ} \mathrm{C}$ and $95^{\circ} \mathrm{C}$ from $325 \mathrm{~nm}$ to $220 \mathrm{~nm}$ with a scan rate of $250 \mathrm{~nm} / \mathrm{min}$ generating 1 data point every $0.42 \mathrm{~nm}$. Monovalent ions $\left(\mathrm{Li}^{+}, \mathrm{Na}^{+}, \mathrm{K}^{+}\right)$were titrated from $1 \mathrm{mM}$ to $58 \mathrm{mM}$ using concentrated stock solutions keeping dilution effects to a minimum. Samples were allowed to equilibrate for 10 min between each ion-titration step. TD spectra were generated by subtracting the normalized high temperature spectrum from the normalized low temperature spectrum. Double difference TD spectra were generated from the $1 \mathrm{mM}$ and $58 \mathrm{mM}$ cation titration spectra followed by normalization to the major peak around $290 \mathrm{~nm}$. All spectra were smoothed by Savitzky-Golay filtering ${ }^{47}$.

UV-melting curves. Pre-mRNA transcripts were dissolved in $0.5 x \mathrm{xE} \mathrm{pH} 7.5(50 \mu \mathrm{L})$, heated to $95^{\circ} \mathrm{C}(2 \mathrm{~min})$ and snap cooled on ice before the addition of concentrated folding buffer to yield a final volume of $0.5 \mathrm{~mL}$ and a final buffer concentration of $5 \mathrm{mM} \mathrm{Na}$-cacodylate $\mathrm{pH} 6.8,70 \mathrm{mM} \mathrm{NaCl}$ and $2 \mathrm{mM} \mathrm{MgCl}_{2}$. RNA concentrations were adjusted to $\mathrm{A}_{260}=0.5$. Denaturation/renaturation profiles were measured at $260 \mathrm{~nm}$ between $20^{\circ} \mathrm{C}$ and $95^{\circ} \mathrm{C}$ at a heating/cooling rate of $1{ }^{\circ} \mathrm{C} / \mathrm{min}$ (data aquisition: 0.3 data points $/{ }^{\circ} \mathrm{C}$ ). Fraction folded $(\alpha)$-plots were generated from the the melting curves as: $\alpha(\mathrm{T})=\mathrm{a} /(\mathrm{a}+\mathrm{b})$; $\mathrm{a}$, b: distances to the upper and lower baselines. Baselines were set by linear regression. Hyperchromicity values $\left(\mathrm{A}_{\text {rel }}\right)$ were calculated by two different procedures. (1) "Nearest neighbor" approach using equation: $A_{\text {rel }}(\%)=\left(\left(\mathrm{A}_{260} \mathrm{RNA}_{\text {unfolded }} /\left(\mathrm{A}_{260} \mathrm{ss}+\mathrm{A}_{260} \mathrm{ds}\right)\right)-1 \times 100\right.$. Molar extinction coefficients of the fully unfolded RNAs, the double-stranded (ds) and the single-stranded (ss) subdomains of the SHAPE-derived 2D-structures were calculated using OligoCalc ${ }^{48}$ followed by a conversion to absorbance values. GQ-forming nucleotides were treated as ss and non-canonical bp were treated as Watson/ Crick bp. (2) "Fractional approach" using equation: $A_{\text {rel }}(\%)=\left(\left(1 / f_{s s}+f_{d s} \times N+f_{G Q} \times M\right)-1\right) \times 100 . M=0.953$ and $\mathrm{N}=0.729$ accounting for $37 \%$ hyperchromicity; $\mathrm{f}=$ fraction.

RNaseH-based "gDNA" annealing assay. The ability of free and editosome-bound pre-mRNAs to form gRNA/pre-mRNA hybrid RNAs was analyzed using a panel of "guiding" (g)DNA oligonucleotides complementary to different regions of the $\mathrm{CYb}$-transcript (see numbers in brackets). The following oligodeoxynucleotides were used: CYb-1 (150-161): ACAAAATATCAA; CYb-2 (227-238): GTAAATATAATA; CYb-3 (255-266): ATTGACTTAAAT; CYb-4 (459-470): TCACTTCCCCAA; CYb-5 (651-662): AACATATCTCTC; CYb-7 (840851): AAAAACAAACCC; CYb-8 (967-978): ACTCATTCATAT; CYb-9 (1045-1056): CAAAAATAATAA. Annealed gDNA/pre-mRNA hybrid molecules were identified by RNaseH cleavage. For that, co-transcriptionally $\left.{ }^{32} \mathrm{P}\right]$-labeled CYb-RNA ( $\left.1 \mathrm{nM}\right)$ was incubated with an eqimolar amount of editosomes and incubated for $15 \mathrm{~min}$ at $27^{\circ} \mathrm{C}$ in EB. After the addition of 10-1000 nM DNA-oligonucleotide $\mathrm{RNaseH}$ cleavage was performed for $20 \mathrm{~min}$ at $27^{\circ} \mathrm{C}$ using $0.01 \mathrm{U} / \mu \mathrm{L}$ E. coli RNaseH. RNA fragments were phenol-extracted followed by EtOH precipitation. Cleavage products were electrophoretically separated in $8 \mathrm{M}$ urea-containing $5 \%(\mathrm{w} / \mathrm{v})$ polyacrylamide gels, visualized by phosphorimaging and densitometrically quantified.

\section{References}

1. Herschlag, D. RNA chaperones and the RNA folding problem. J. Biol. Chem. 270, 20871-20874 (1995).

2. Rajkowitsch, L. et al. RNA chaperones, RNA annealers and RNA helicases. RNA Biol. 4, 118-130 (2007).

3. Woodson, S. A. Taming free energy landscapes with RNA chaperones. RNA Biol. 7, 677-686 (2010).

4. Grohman, J. K. et al. A guanosine-centric mechanism for RNA chaperone function. Science 340, 190-195 (2013).

5. Russell, R. RNA misfolding and the action of chaperones. Front. Biosci. 13, 1-20 (2008). 
6. Aphasizhev, R. \& Aphasizheva, I. Mitochondrial RNA editing in trypanosomes: small RNAs in control. Biochimie 100, 125-131 (2014).

7. Göringer, H. U. 'Gestalt', composition and function of the Trypanosoma brucei editosome. Annu Rev Microbiol. 66, 65-82 (2012).

8. Müller, U. F. \& Göringer, H. U. Mechanism of the gBP21-mediated RNA/RNA annealing reaction: matchmaking and charge reduction. Nucleic Acids Res. 30, 447-455 (2002).

9. Missel, A., Souza, A. E., Nörskau, G. \& Göringer, H. U. Disruption of a gene encoding a novel mitochondrial DEAD-box protein in Trypanosoma brucei affects edited mRNAs. Mol. Cell. Biol. 17, 4895-4903 (1997).

10. Li, F., Herrera, J., Zhou, S., Maslov, D. A. \& Simpson, L. Trypanosome REH1 is an RNA helicase involved with the 3'-5' polarity of multiple gRNA-guided uridine insertion/deletion RNA editing. Proc. Natl. Acad. Sci. USA. 108, 3542-3547 (2011).

11. Kruse, E., Voigt, C., Leeder, W.-M. \& Göringer, H. U. RNA helicases involved in U-insertion/deletion-type RNA editing. Biochim. Biophys. Acta 1829, 835-841 (2013).

12. Böhm, C., Katari, V. S., Brecht, M. \& Göringer, H. U. Trypanosoma brucei 20 S editosomes have one RNA substrate-binding site and execute RNA unwinding activity. J. Biol. Chem. 287, 26268-26277 (2012).

13. Merino, E. J., Wilkinson, K. A., Coughlan, J. L. \& Weeks, K. M. RNA structure analysis at single nucleotide resolution by selective 2'-hydroxyl acylation and primer extension (SHAPE). J. Am. Chem. Soc. 127, 4223-4231 (2005).

14. Low, J. T. \& Weeks, K. M. SHAPE-directed RNA secondary structure prediction. Methods 52, 150-158 (2010).

15. Weeks, K. M. Toward all RNA structures, concisely. Biopolymers 103, 438-448 (2015).

16. Mortimer, S. A. \& Weeks, K. M. A fast-acting reagent for accurate analysis of RNA secondary and tertiary structure by SHAPE chemistry. J. Am. Chem. Soc. 129, 4144-4145 (2007).

17. McGinnis, J. L., Dunkle, J. A., Cate, J. H. \& Weeks, K. M. The mechanisms of RNA SHAPE chemistry. J. Am. Chem. Soc. 134, 6617-6624 (2012).

18. Hofacker, I. L. Vienna RNA secondary structure server. Nucleic Acids Res. 31, 3429-3431 (2003).

19. Reuter, J. S. \& Mathews, D. H. RNAstructure: software for RNA secondary structure prediction and analysis. BMC Bioinformatics 11, 129 (2010).

20. Millevoi, S., Moine, H. \& Vagner, S. G-quadruplexes in RNA biology. Wiley Interdiscip. Rev. RNA 3, 495-507 (2012).

21. Shrestha, P., Xiao, S., Dhakal, S., Tan, Z. \& Mao, H. Nascent RNA transcripts facilitate the formation of G-quadruplexes. Nucleic Acids Res. 42, 7236-7246 (2014).

22. Mergny, J. L., Phan, A. T. \& Lacroix, L. Following G-quartet formation by UV-spectroscopy. FEBS Lett. 435, 74-78 (1998).

23. Mergny, J. L., Li, J., Lacroix, L., Amrane, S. \& Chaires, J. B. Thermal difference spectra: a specific signature for nucleic acid structures. Nucleic Acids Res. 33, e138 (2005).

24. Zheng, K. W. et al. A competitive formation of DNA:RNA hybrid G-quadruplex is responsible to the mitochondrial transcription termination at the DNA replication priming site. Nucleic Acids Res. 42, 10832-10844 (2014).

25. Wu, R. Y., Zheng, K. W., Zhang, J. Y., Hao, Y. H. \& Tan, Z. Formation of DNA:RNA hybrid G-quadruplex in bacterial cells and its dominance over the intramolecular DNA G-quadruplex in mediating transcription termination. Angew. Chem. Int. Ed. Engl. 54, 2447-2451 (2015).

26. Hajdin, C. E. et al. Accurate SHAPE-directed RNA secondary structure modeling, including pseudoknots. Proc. Natl. Acad. Sci. USA 110, 5498-5503 (2013).

27. Vendeix, F. A., Munoz, A. M. \& Agris, P. F. Free energy calculation of modified base-pair formation in explicit solvent: A predictive model. RNA 15, 2278-2287 (2009).

28. Lorentzen, E., Basquin, J., Tomecki, R., Dziembowski, A. \& Conti, E. Structure of the active subunit of the yeast exosome core, Rrp44: diverse modes of substrate recruitment in the RNase II nuclease family. Mol. Cell 29, 717-728 (2008).

29. Bonneau, F., Basquin, J., Ebert, J., Lorentzen, E. \& Conti, E. The yeast exosome functions as a macromolecular cage to channel RNA substrates for degradation. Cell 139, 547-559 (2009).

30. Czerwoniec, A., Kasprzak, J. M., Bytner, P., Dobrychłop, M. \& Bujnicki, J. M. Structure and intrinsic disorder of the proteins of the Trypanosoma brucei editosome. FEBS Lett. 589, 2603-2610 (2015).

31. Tompa, P. \& Csermely, P. The role of structural disorder in the function of RNA and protein chaperones. FASEB J. 18, 1169-1175 (2004).

32. Dethoff, E. A., Chugh, J., Mustoe, A. M. \& Al-Hashimi, H. M. Functional complexity and regulation through RNA dynamics. Nature 482, 322-330 (2012).

33. Bokinsky, G. et al. Two distinct binding modes of a protein cofactor with its target RNA. J. Mol. Biol. 361, 771-784 (2006).

34. Shajani, Z., Drobny, G. \& Varani, G. Binding of U1A protein changes RNA dynamics as observed by ${ }^{13} \mathrm{C}$ NMR relaxation studies. Biochemistry 46, 5875-5883 (2007).

35. Kim, H. et al. Protein-guided RNA dynamics during early ribosome assembly. Nature 506, 334-338 (2014).

36. Cross, G. A. Identification, purification and properties of clone specific glycoprotein antigens constituting the surface coat of Trypanosoma brucei. Parasit. 71, 393-417 (1975).

37. Brun, R. \& Schönenberger, M. Cultivation and in vitro cloning or procyclic culture forms of Trypanosoma brucei in a semi-defined medium. Acta Tropica 36, 289-292 (1979).

38. Hauser, R., Pypaer, M., Häusler, T., Horn, E. K. \& Schneider, A. In vitro import of proteins into mitochondria of Trypanosoma brucei and Leishmania tarentolae. J. Cell Sci. 109, 517-523 (1996)

39. Göringer, H. U., Koslowsky, D. J., Morales, T. H. \& Stuart, K. The formation of mitochondrial ribonucleoprotein complexes involving guide RNA molecules in Trypanosoma brucei. Proc. Natl. Acad. Sci. USA 91, 1776-1780 (1994).

40. Igo, R. P. Jr., Palazzo, S. S., Burgess, M. L., Panigrahi, A. K. \& Stuart, K. Uridylate addition and RNA ligation contribute to the specificity of kinetoplastid insertion RNA editing. Mol. Cell. Biol. 20, 8447-8457 (2000).

41. Igo, R. P. Jr. et al. Role of uridylate-specific exoribonuclease activity in Trypanosoma brucei RNA editing. Eukar. Cell 1, 112-118 (2002).

42. Katari, V. S., van Esdonk, L. \& Göringer, H. U. Molecular crowding inhibits U-insertion/deletion RNA editing in vitro: consequences for the in vivo reaction. PLoS One 8, e83796 (2013).

43. Turner, R., Shefer, K. \& Ares, M. Jr. Safer one-pot synthesis of the 'SHAPE' reagent 1-methyl-7-nitroisatoic anhydride (1m7). RNA 19, 1857-1863 (2013).

44. Vasa, S. M., Guex, N., Wilkinson, K. A., Weeks, K. M. \& Giddings, M. C. ShapeFinder: a software system for high-throughput quantitative analysis of nucleic acid reactivity information resolved by capillary electrophoresis. RNA 14, 1979-1990 (2008).

45. Deigan, K. E., Li, T. W., Mathews, D. H. \& Weeks, K. M. Accurate SHAPE-directed RNA structure determination. Proc. Natl. Acad. Sci. USA. 106, 97-102 (2009).

46. Lorenz, R. et al. 2D meets 4 G: G-quadruplexes in RNA secondary structure prediction. IEEE/ACM Trans. Comput. Biol. Bioinform. 10, 832-844 (2013)

47. Savitzky, A. \& Golay, M. J. E. Smoothing and differentiation of data by simplified least squares procedures. Anal. Chem. 36, $1627-1639$ (1964).

48. Kibbe, W. A. OligoCalc: an online oligonucleotide properties calculator. Nucleic Acids Res. 35 (Web Server issue), W43-46 (2007). 


\section{Acknowledgements}

We thank Anne Liston and Mike Roskop for discussions and Elisabeth Kruse and Pedro Morais for critically reviewing the manuscript. Anne Kleinert and Stephan Voskuhl are acknowledged for their contributions at the start of the project. Geoffrey Schladow is thanked for his hospitality during a sabbatical at UC Davis-TERC. This work was supported by the German Research Foundation (DFG-SFB902) and the Dr. Illing Foundation for Molecular Chemistry to HUG.

\section{Author Contributions}

All authors contributed to the design of the experiments and the analysis of the data. The experiments were conducted by W.-M.L., C.V. and M.B. The manuscript was written by H.U.G.

\section{Additional Information}

Supplementary information accompanies this paper at http://www.nature.com/srep

Competing financial interests: The authors declare no competing financial interests.

How to cite this article: Leeder, W.-M. et al. The RNA chaperone activity of the Trypanosoma brucei editosome raises the dynamic of bound pre-mRNAs. Sci. Rep. 6, 19309; doi: 10.1038/srep19309 (2016).

(c) (i) This work is licensed under a Creative Commons Attribution 4.0 International License. The images or other third party material in this article are included in the article's Creative Commons license, unless indicated otherwise in the credit line; if the material is not included under the Creative Commons license, users will need to obtain permission from the license holder to reproduce the material. To view a copy of this license, visit http://creativecommons.org/licenses/by/4.0/ 